\title{
Article \\ Factors Associated with Postpartum Post-Traumatic Stress Disorder (PTSD) Following Obstetric Violence: A Cross-Sectional Study
}

\author{
Sergio Martinez-Vázquez ${ }^{1}$, Julián Rodríguez-Almagro ${ }^{2}$, , Antonio Hernández-Martínez ${ }^{2, *}$ (D) \\ and Juan Miguel Martínez-Galiano ${ }^{1,3}$ \\ 1 Department of Nursing, University of Jaen, 23071 Jaen, Spain; svazquez@ujaen.es (S.M.-V.); \\ jgaliano@ujaen.es (J.M.M.-G.) \\ 2 Department of Nursing, Faculty of Nursing of Ciudad Real, The University of Castilla-La Mancha, \\ 13071 Ciudad Real, Spain; JulianJ.Rodriguez@uclm.es \\ 3 Consortium for Biomedical Research in Epidemiology and Public Health (CIBERESP), 28029 Madrid, Spain \\ * Correspondence: Antonio.HMartinez@uclm.es; Tel.: +34-625300374
}

\section{check for}

updates

Citation: Martinez-Vázquez, S.;

Rodríguez-Almagro, J.;

Hernández-Martínez, A.;

Martínez-Galiano, J.M. Factors

Associated with Postpartum

Post-Traumatic Stress Disorder

(PTSD) Following Obstetric Violence:

A Cross-Sectional Study. J. Pers. Med.

2021, 11, 338. https://doi.org/

10.3390/jpm11050338

Academic Editor: Moon-Soo Lee

Received: 8 April 2021

Accepted: 23 April 2021

Published: 24 April 2021

Publisher's Note: MDPI stays neutral with regard to jurisdictional claims in published maps and institutional affiliations.

Copyright: (c) 2021 by the authors. Licensee MDPI, Basel, Switzerland. This article is an open access article distributed under the terms and conditions of the Creative Commons Attribution (CC BY) license (https:/ / creativecommons.org/licenses/by/ $4.0 /)$.
Abstract: To determine the association between experiencing obstetric violence and the incidence of postpartum post-traumatic stress disorder (PTSD). A cross-sectional study with puerperal women was conducted in Spain following ethical approval. The Perinatal Posttraumatic Stress Disorder Questionnaire (PPQ) was administered online. Sociodemographic, clinical, and obstetric violence variables and the risk of dichotomized PTSD (low/high) were studied by bivariate and multivariate analysis with binary logistic regression. 955 women were invited to participate. 53 women refused to participate, three did not complete all survey questions and, finally, 899 women were included. The risk of PTSD (score $\geq 19$ ) using the PPQ was $12.7 \%$ (114). The mean score was 9.10 points $(\mathrm{SD}=8.52)$. Risk factors identified were having a delivery plan that was not respected (aOR: 2.85, 95\% CI 1.56-5.21), elective caesarean delivery (aOR: 2.53, 95\% CI 1.02-2.26), emergency caesarean section (aOR: $3.58,95 \%$ CI 1.83-6.99), admission of the newborn to the neonatal intermediate care unit (aOR: 4.95, 95\% CI 2.36-10.36), admission to the intensive care unit (aOR: 2.25, 95\% CI 1.02-4.97), formula feeding on discharge (aOR: 3.57, 95\% CI 1.32-9.62), verbal obstetric violence (aOR: 5.07, 95\% CI 2.98-8.63), and psycho-affective obstetric violence (aOR: 2.61, 95\% CI 1.45-4.67). Various clinical practices were identified with the risk of PTSD, highlighting various types of obstetric violence. Partner support and early breastfeeding were identified as protective factors. Sensitizing professionals is essential to prevent the risk of PTSD.

Keywords: obstetric violence; post-traumatic stress disorder (PTSD); associated factors; puerperium; postpartum

\section{Introduction}

Pregnancy, childbirth, and postpartum are periods in which a woman's risk of developing a mental disorder increases; despite this, mental health is an aspect that does not usually receive a lot of attention in the care provided during these periods [1,2].

Postpartum post-traumatic stress disorder (PTSD) is one of these disorders and may be present in $0.8-43 \%$ of women, depending on whether the assessment uses only selfdeclared symptoms, the diagnostic criteria of the DSM, or if the study has been carried out at a community level or in the at-risk population [3-8].

Women who experience this disorder report re-experimentation of the event, a feeling of disconnection from the baby, absence of reality, nightmares, irritability, rejection of new motherhood, or may even develop tocophobia (the fear of pregnancy and childbirth) [9-14].

The maximum expression of these symptoms appears between 4-6 weeks postpartum, although the symptoms can remain for months or years later, and even in future pregnancies $[3,15]$. 
Different variables have been associated with the risk of developing PTSD, such as having been abused during childhood [16], exposure to trauma [17], the type of delivery, the Kristeller maneuver being performed in the expulsive period, having third or fourth-degree perineal tears [18], having a postpartum hemorrhage [19], or being afraid of childbirth [20]. In addition, age, parity, and having resources, such as coping skills, have also been associated with the incidence of PTSD [21,22].

Postpartum PTSD affects maternal morbidity [11,14] It can also affect the couple, the familial environment, the family, and, especially, the baby $[12,23,24]$ It has also been associated with a lower rate of breastfeeding initiation [24] and a higher incidence of low birth weight [4].

In the care that women receive during childbirth, they may experience obstetric violence, also called incorrect or inappropriate treatment [25], either physically or emotionally with inadequate clinical care or with violation of the principle of autonomy [26]. In some countries, a frequency of $35.4 \%$ has been reported for physical, verbal, or discrimination abuse [27], reaching 91.7\% in some studies for abuse and lack of respect [28]. In other countries such as Spain, the prevalence of obstetric violence is around 67\% [29]. Due to this, the World Health Organization (WHO) has carried out a strategy aimed at health professionals to alert them on this issue [30].

Obstetric violence and the incidence of PSTD have been studied by several authors [31,32]. In a meta-analysis with 50 studies, it was suggested that a negative experience during delivery was a risk factor for the appearance of PTSD, prompted, among other reasons, by lack of support or type of delivery, i.e., whether it was instrumental or caesarean [31]. In addition, subjective distress generated by experiences during childbirth appears to be an important predictor for the development of PTSD and was the main risk factor in the 31 studies analyzed in a systematic review carried out in 2012 [32].

Establishing a possible association between experiencing obstetric violence and the incidence of PTSD will help sensitize health professionals who provide care during pregnancy, childbirth, and the postpartum period; promoting strategies with correct and evidence-based clinical practices and reducing the medicalization of the natural childbirth process [33]. In this way, the incidence of PTSD and its resulting consequences for maternal and newborn health could be reduced $[11,12,34]$. Therefore, the present study intended to determine if there is an association between experiencing obstetric violence and the risk of PTSD.

\section{Methodology}

\subsection{Design and Participants}

A cross-sectional study was conducted with women who had given birth in Spain. The inclusion criteria were postpartum women whose delivery had been in the last 12 months, and who were of legal age. The only exclusion criteria were not being able to understand the Spanish language, and that a minimum of one month had not elapsed since the date of birth. Data collection was carried out from September to December 2019. This study received the approval of the Research Ethics Committee of the province of Jaen with reference number TD-VCDEPP-2019/1417-N-19. All women were required to read the study information and then give their digital consent by checking a box, including the fact that participation was entirely voluntary with anonymity guaranteed.

For calculating the sample size, the maximum modelling criterion was used where 10 events (women at risk of PTSD) are included for each independent variable to be introduced in the multivariate model [35]. Considering the prevalence of PTSD risk was $10 \%$ in previous studies in Spain [36], 80 women at risk of PTSD would be needed to include eight variables and a minimum of 800 women included in the study.

\subsection{Data Collection and Information Sources}

Data was collected using a previously piloted online questionnaire that we had constructed for this purpose. The questionnaire collected information on sociodemographic 
variables, clinical variables, and variables related to the woman's experience with childbirth care, among other information.

The main independent variable was obstetric violence and its three components, verbal, physical, and psycho-affective. A questionnaire was used to determine its occurrence by asking about various practices and situations that the woman had experienced during her labor process. (Annex 1. Obstetric violence questionnaire).

The main outcome variable was the risk of PTSD, which was assessed using the Perinatal Post-traumatic Stress Disorder Questionnaire (PPQ) [37]. The PPQ consists of 14 questions with Likert-type answers with scores ranging from 0 to 56 points. A high risk of PTSD score was considered as a score of 19 points or higher.

The dissemination of the questionnaire was carried out thanks to the collaboration of the different associations of Spanish midwives who distributed the questionnaire among the women to whom they provided their care.

\subsection{Statistical Analysis}

First, descriptive statistics were performed using absolute and relative frequencies for categorical variables and mean with standard deviation for quantitative variables. Next, a bivariate analysis was performed between the sociodemographic, clinical, and obstetric violence variables and the risk of PTSD (dichotomized as low risk/high risk). Crude $(\mathrm{OR})$ and adjusted (aOR) odds ratios were estimated with corresponding 95\% confidence intervals, utilizing a bivariate and multivariate analysis with binary logistic regression, respectively. For the multivariate analysis, the SPSS backward step procedure was used.

\section{Results}

\section{Characteristics of Participants}

955 women were invited to participate. 53 women refused to participate, three did not complete all survey questions, and finally 899 women were included. The mean age of the participants was 35.2 years ( $\mathrm{SD}=4.25$ years), and $87.9 \%$ (736) had their delivery within the network of Spanish public hospitals, $92.9 \%$ (835) had a planned pregnancy, and $96.6 \%$ (863) of the sample were Spanish. Further sociodemographic and clinical information that characterizes the sample can be found in Table 1.

Subsequently, the risk of PTSD was determined (with a score $\geq$ of 19 ) and found $12.7 \%$ (114) had a high risk of PTSD, with a mean score in the PPQ questionnaire of 9.10 points $(\mathrm{SD}=8.52)$ (Figure 1).

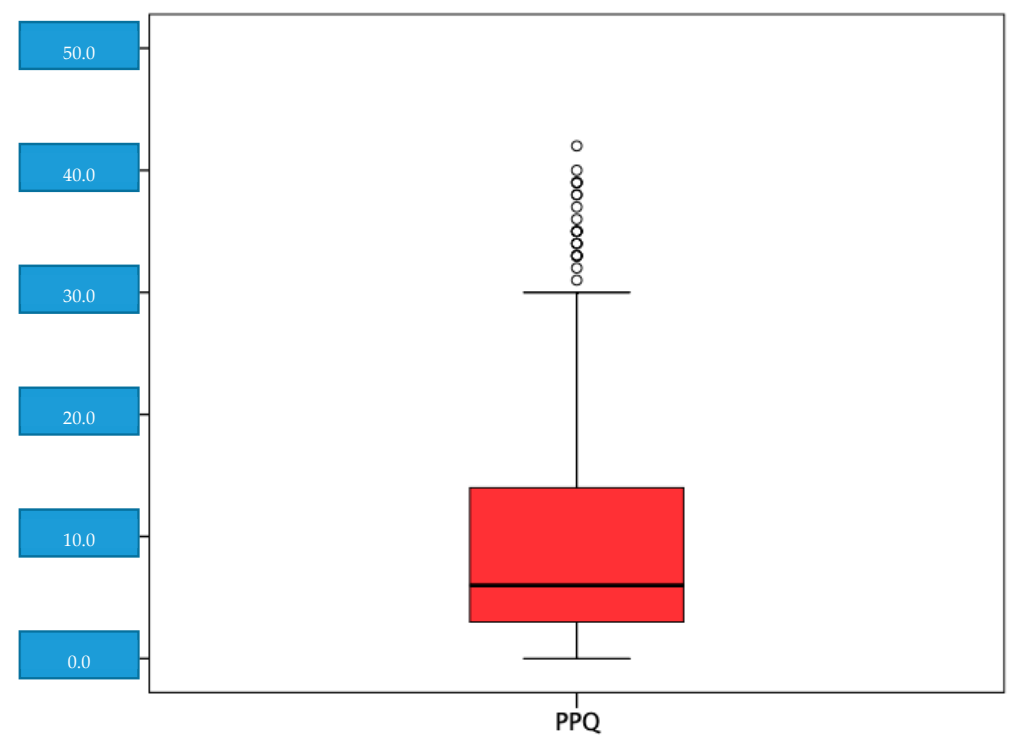

Figure 1. Distribution of the scores in the perinatal post-traumatic stress questionnaire (PPQ). 
Table 1. Sociodemographic and current pregnancy characteristics of the sample.

\begin{tabular}{|c|c|c|}
\hline Variable & $n(\%)$ & Mean (SD) \\
\hline Maternal age & & $35.2(4.25)$ \\
\hline $\begin{array}{l}\text { Weight before pregnancy } \\
\text { (mean) }\end{array}$ & & $65.8(13.24)$ \\
\hline $\begin{array}{l}\text { Weight after pregnancy } \\
\text { (mean) }\end{array}$ & & $77.3(12.96)$ \\
\hline Months from last child & & $5.4(3.42)$ \\
\hline Pre-gestational BMI & & $24.4(4.85)$ \\
\hline \multicolumn{3}{|l|}{ Education level } \\
\hline Primary school & $15(1.7)$ & \\
\hline Secondary school & $61(6.8)$ & \\
\hline High school & $199(22.1)$ & \\
\hline University & $624(69.4)$ & \\
\hline \multicolumn{3}{|l|}{ Current working status } \\
\hline Full-time work & $277(30.8)$ & \\
\hline Part-time work & $131(14.6)$ & \\
\hline Sick leave & $189(21.0)$ & \\
\hline Unpaid leave & $103(11.5)$ & \\
\hline Unemployed & $199(22.1)$ & \\
\hline \multicolumn{3}{|l|}{ Nationality } \\
\hline Spanish & $868(96.6)$ & \\
\hline Other & $31(3.4)$ & \\
\hline \multicolumn{3}{|l|}{ Family monthly wage } \\
\hline Less than 1000 euros & $46(5.1)$ & \\
\hline Between 1000 and 2000 euros & $319(35.5)$ & \\
\hline Between 2000 and 3000 euros & $282(31.4)$ & \\
\hline Between 3000 and 4000 euros & $78(8.7)$ & \\
\hline \multicolumn{3}{|l|}{ Planned pregnancy } \\
\hline No & $64(7.1)$ & \\
\hline Yes & $835(92.9)$ & \\
\hline \multicolumn{3}{|l|}{ Number of pregnancies } \\
\hline One & $363(40.4)$ & \\
\hline Two & $329(36.6)$ & \\
\hline Three & $138(15.4)$ & \\
\hline Four & $45(5)$ & \\
\hline Five or more & $24(2.7)$ & \\
\hline \multicolumn{3}{|l|}{ Number of vaginal births } \\
\hline None & $170(18.9)$ & \\
\hline One & $402(44.7)$ & \\
\hline Two & $283(31.5)$ & \\
\hline Three or more & $43(4.8)$ & \\
\hline \multicolumn{3}{|l|}{ Place of birth } \\
\hline Public hospital & $736(81.9)$ & \\
\hline Private hospital & $152(16.9)$ & \\
\hline Midwife-led hospital & $3(0.3)$ & \\
\hline Home & $8(0.9)$ & \\
\hline PPQ & & $9.10(8.52)$ \\
\hline Score $<19$ & $785(87.3)$ & \\
\hline Score $\geq 19$ & $114(12.7)$ & \\
\hline
\end{tabular}

Next, a bivariate analysis was conducted, and an association between the risk of PTSD with 19 variables was observed, including global obstetric violence and the verbal, physical, and psycho-affective subtypes. (Table 2). 
Table 2. Bivariate and multivariate analysis between sociodemographic and obstetric characteristics. Obstetric violence and PTSD.

\begin{tabular}{|c|c|c|c|c|}
\hline \multirow[t]{2}{*}{ Variable } & \multicolumn{4}{|c|}{ Obstetric Violence \& PTSD Risk } \\
\hline & Score $<19$ & Score $\geq 19$ & OR $(95 \% \mathrm{CI})$ & aOR $(95 \% \mathrm{CI})$ \\
\hline \multicolumn{5}{|l|}{ Maternal age } \\
\hline$\leq 35$ years & $404(87.3)$ & $59(12.7)$ & 1 (ref.) & \\
\hline$>35$ years & $381(87.4)$ & $55(12.6)$ & $0.99(0.67,1.47)$ & \\
\hline \multicolumn{5}{|l|}{ Academic level } \\
\hline Primary school & $15(100.0)$ & $0(0.0)$ & & \\
\hline Secondary school & $53(88.3)$ & $7(11.7)$ & $\mathrm{NC}$ & \\
\hline High school & $173(86.9)$ & $26(13.1)$ & $\mathrm{NC}$ & \\
\hline University & $544(87.0)$ & $81(13.0)$ & $\mathrm{NC}$ & \\
\hline \multicolumn{5}{|l|}{ Current working status } \\
\hline Full-time work & $242(87.4)$ & $35(12.6)$ & 1 (ref.) & \\
\hline Part-time work & $113(86.3)$ & $18(13.7)$ & $1.10(0.60,2.02)$ & \\
\hline Sick leave & $167(88.4)$ & $22(11.6)$ & $0.91(0.52,1.61)$ & \\
\hline Unpaid leave & $88(85.4)$ & $15(14.6)$ & $1.18(0.61,2.26)$ & \\
\hline Unemployed & $175(87.9)$ & $24(12.1)$ & $0.95(0.55,1.65)$ & \\
\hline \multicolumn{5}{|l|}{ Nationality } \\
\hline Spanish & $760(87.6)$ & $108(12.4)$ & 1 (ref.) & \\
\hline Other & $25(80.6)$ & $6(19.4)$ & $1.69(0.68,4.21)$ & \\
\hline \multicolumn{5}{|l|}{ Family monthly wage } \\
\hline Less than 1000 euros & $40(87.0)$ & $6(13.0)$ & 1 (ref.) & \\
\hline Between 1000 and 2000 euros & $271(85.0)$ & $48(15.0)$ & $1.18(0.48,2.94)$ & \\
\hline Between 2000 and 3000 euros & $251(89.0)$ & $31(11.0)$ & $0.82(0.32,2.10)$ & \\
\hline Between 3000 and 4000 euros & $154(88.5)$ & $20(11.5)$ & $0.87(0.33,2.30)$ & \\
\hline More than 4000 euros & $69(88.5)$ & $9(11.5)$ & $0.87(0.29,2.62)$ & \\
\hline \multicolumn{5}{|l|}{ Planned pregnancy } \\
\hline No & $56(87.5)$ & $8(12.5)$ & 1 (ref.) & \\
\hline Yes & $729(87.3)$ & $106(12.7)$ & $1.02(0.47,2.20)$ & \\
\hline \multicolumn{5}{|l|}{ Maternal antenatal classes } \\
\hline No & $161(89.0)$ & $20(11.0)$ & 1 (ref.) & \\
\hline Yes (less than 5 classes) & $113(85.6)$ & $19(14.4)$ & $1.35(0.69,2.65)$ & \\
\hline Yes (more than 5 classes) & $511(87.2)$ & $75(12.8)$ & $1.18(0.70,2.00)$ & \\
\hline \multicolumn{5}{|l|}{ Birth plan } \\
\hline No & $436(89.7)$ & $50(10.3)$ & 1 (ref.) & 1 (ref.) \\
\hline Yes, but not respected & $59(60.8)$ & $38(39.2)$ & $5.62(3.40,9.28)$ & $2.85(1.56,5.21)$ \\
\hline Yes, and was respected & $290(91.8)$ & $26(8.2)$ & $0.78(0.48,1.29)$ & $1.49(0.82,2.70)$ \\
\hline \multicolumn{5}{|l|}{ Twin pregnancy } \\
\hline No & $769(87.3)$ & $112(12.7)$ & 1 (ref.) & \\
\hline Yes & $16(88.9)$ & $2(11.1)$ & $0.86(0.20,3.78)$ & \\
\hline \multicolumn{5}{|l|}{ Live newborn } \\
\hline No & $3(50.0)$ & $3(50.0)$ & 1 (ref.) & \\
\hline Yes & $782(87.6)$ & $111(12.4)$ & $0.14(0.03,0.71)$ & \\
\hline \multicolumn{5}{|l|}{ Parity } \\
\hline Primiparous & & & 1 (ref.) & \\
\hline & & & $0.40(0.25,0.65)$ & \\
\hline \multicolumn{5}{|l|}{ Induction of labour } \\
\hline No & $491(89.8)$ & $56(10.2)$ & 1 (ref.) & \\
\hline Yes & $294(83.5)$ & $58(16.5)$ & $1.73(1.17,2.57)$ & \\
\hline \multicolumn{5}{|l|}{ Natural analgesia } \\
\hline No & $631(86.7)$ & $97(13.3)$ & 1 (ref.) & \\
\hline Yes & $154(90.1)$ & $17(9.9)$ & $0.72(0.42,1.24)$ & \\
\hline \multicolumn{5}{|l|}{ Regional analgesia } \\
\hline No & $232(91.0)$ & $23(9.0)$ & 1 (ref.) & \\
\hline Yes & $553(85.9)$ & $91(14.1)$ & $1.66(1.03,2.69)$ & \\
\hline \multicolumn{5}{|l|}{ General anaesthesia } \\
\hline No & $763(87.8)$ & $106(12.2)$ & 1 (ref.) & \\
\hline Yes & $22(73.3)$ & $8(26.7)$ & $2.62(1.14,6.03)$ & \\
\hline
\end{tabular}


Table 2. Cont.

\begin{tabular}{|c|c|c|c|c|}
\hline \multirow[t]{2}{*}{ Variable } & \multicolumn{4}{|c|}{ Obstetric Violence \& PTSD Risk } \\
\hline & Score $<19$ & Score $\geq 19$ & OR $(95 \% \mathrm{CI})$ & aOR $(95 \% \mathrm{CI})$ \\
\hline \multicolumn{5}{|l|}{ Type of birth } \\
\hline Normal vaginal delivery & $500(92.8)$ & $39(7.2)$ & 1 (ref.) & 1 (ref.) \\
\hline Instrumental & $150(88.2)$ & $20(11.8)$ & $1.39(0.92,2.09)$ & $1.08(0.56,2.11)$ \\
\hline Elective C/S & $48(80.0)$ & $12(20.0)$ & $1.08(0.56,2.08)$ & $2.53(1.02,2.26)$ \\
\hline Emergency C/S & $87(66.9)$ & $43(33.1)$ & $2.09(1.35,3.23)$ & $3.58(1.83,6.99)$ \\
\hline \multicolumn{5}{|l|}{ Episiotomy } \\
\hline No & $567(86.2)$ & $91(13.8)$ & 1 (ref.) & \\
\hline Yes & $218(90.5)$ & $23(9.5)$ & $0.66(0.41,1.07)$ & \\
\hline \multicolumn{5}{|l|}{ Perineal tear } \\
\hline No & $453(84.5)$ & $83(15.5)$ & 1 (ref.) & \\
\hline Mild & $306(92.2)$ & $26(7.8)$ & $0.46(0.29,0.74)$ & \\
\hline Severe & $26(83.9)$ & $5(16.1)$ & $1.05(0.39,2.81)$ & \\
\hline \multicolumn{5}{|l|}{ Skin-to-skin } \\
\hline No & $135(71.4)$ & $54(28.6)$ & 1 (ref.) & \\
\hline Yes & $650(91.5)$ & $60(8.5)$ & $0.23(0.15,0.35)$ & \\
\hline \multicolumn{5}{|c|}{ Breastfeeding $1 \mathrm{~h}$ after childbirth } \\
\hline No & $171(78.1)$ & $48(21.9)$ & 1 (ref.) & 1 (ref.) \\
\hline Yes & $614(90.3)$ & $66(9.7)$ & $0.38(0.25,0.58)$ & $0.48(0.26,0.87)$ \\
\hline \multicolumn{5}{|c|}{$\begin{array}{l}\text { Admission of the new born to care } \\
\text { unit }\end{array}$} \\
\hline No & $699(89.8)$ & $79(10.2)$ & 1 (ref.) & 1 (ref.) \\
\hline Intermediate care & $38(64.4)$ & $21(35.6)$ & $4.89(2.73,8.75)$ & $4.95(2.36,10.36)$ \\
\hline NICU & $48(77.4)$ & $14(22.6)$ & $2.58(1.36,4.89)$ & $2.25(1.02,4.97)$ \\
\hline \multicolumn{5}{|l|}{ Place of birth } \\
\hline Public hospital & $646(87.8)$ & $90(12.2)$ & 1 (ref.) & \\
\hline Private hospital & $128(84.2)$ & $24(15.8)$ & $1.35(0.83,2.19)$ & \\
\hline Midwife-led hospital & $3(100.0)$ & $0(0.0)$ & $0.00(0.00,0.00)$ & \\
\hline Home & $8(100.0)$ & $0(0.0)$ & $0.00(0.00,0.00)$ & \\
\hline \multicolumn{5}{|l|}{ Hospital length of stay } \\
\hline 1 day & $66(94.3)$ & $4(5.7)$ & 1 (ref.) & \\
\hline 2 day & $412(93.2)$ & $30(6.8)$ & $1.20(0.41,3.52)$ & \\
\hline 3 day & $203(83.9)$ & $39(16.1)$ & $3.17(1.09,9.20)$ & \\
\hline 4 days or more & $104(71.7)$ & $41(28.3)$ & $6.51(2.23,19.00)$ & \\
\hline \multicolumn{5}{|c|}{ Partner support during childbirth } \\
\hline None & $8(44.4)$ & $10(55.6)$ & 1 (ref.) & 1 (ref.) \\
\hline Little & $19(54.3)$ & $16(45.7)$ & $0.67(0.22,2.11)$ & $0.74(0.19,2.86)$ \\
\hline Something & $47(83.9)$ & $9(16.1)$ & $0.15(0.05,0.49)$ & $0.16(0.04,0.63)$ \\
\hline Quite & $198(88.0)$ & $27(12.0)$ & $0.11(0.04,0.30)$ & $0.17(0.05,0.57)$ \\
\hline A lot & $513(90.8)$ & $52(9.2)$ & $0.08(0.03,0.21)$ & $0.17(0.06,0.53)$ \\
\hline \multicolumn{5}{|c|}{ Infant feeding on discharge } \\
\hline Maternal & $362(90.0)$ & $70(10.0)$ & 1 (ref.) & 1 (ref.) \\
\hline Mixed & $126(78.3)$ & $35(21.7)$ & $2.51(1.60,3.91)$ & $1.42(0.81,2.49)$ \\
\hline Artificial & $27(75.0)$ & $9(25.0)$ & $3.01(1.36,6.66)$ & $3.57(1.32,9.69)$ \\
\hline \multicolumn{5}{|c|}{ Postpartum surgical intervention } \\
\hline No & $759(88.1)$ & $103(11.9)$ & 1 (ref.) & \\
\hline Yes & $26(70.3)$ & $11(29.7)$ & $3.12(1.50,6.50)$ & \\
\hline \multicolumn{5}{|l|}{ Maternal ITU admission } \\
\hline No & $785(87.3)$ & $114(12.7)$ & $\mathrm{NC}$ & \\
\hline Yes & $0(0.0)$ & $0(0.0)$ & & \\
\hline \multicolumn{5}{|l|}{ Hospital readmission } \\
\hline No & $764(87.6)$ & $108(12.4)$ & 1 (ref.) & \\
\hline Yes & $21(77.8)$ & $6(22.2)$ & $2.02(0.80,5.12)$ & \\
\hline \multicolumn{5}{|l|}{ Verbal violence } \\
\hline No & $632(93.9)$ & $41(6.1)$ & 1 (ref.) & 1 (ref.) \\
\hline Yes & $153(67.7)$ & $73(32.3)$ & $7.36(4.83,11.21)$ & $5.07(2.98,8.63)$ \\
\hline
\end{tabular}


Table 2. Cont.

\begin{tabular}{|c|c|c|c|c|}
\hline \multirow[t]{2}{*}{ Variable } & \multicolumn{4}{|c|}{ Obstetric Violence \& PTSD Risk } \\
\hline & Score $<19$ & Score $\geq 19$ & OR $(95 \% \mathrm{CI})$ & aOR $(95 \% \mathrm{CI})$ \\
\hline \multicolumn{5}{|c|}{ Physical violence } \\
\hline No & $381(93.2)$ & $28(6.8)$ & 1 (ref.) & \\
\hline Yes & $404(82.4)$ & $86(17.6)$ & $2.90(1.85,5.54)$ & \\
\hline \multicolumn{5}{|c|}{ Psych-affective violence } \\
\hline No & $544(95.6)$ & $25(4.4)$ & 1 (ref.) & 1 (ref.) \\
\hline Yes & $241(83.0)$ & $89(27.0)$ & $8.04(5.03,12.84)$ & $2.61(1.45,4.67)$ \\
\hline \multicolumn{5}{|c|}{ Violence (dichotomous) } \\
\hline No & $283(96.6)$ & $10(3.4)$ & 1 (ref.) & \\
\hline Yes & $502(82.8)$ & $104(17.2)$ & $5.86(3.02,11.40)$ & \\
\hline
\end{tabular}

Bold: Statistically significant differences. OR: Odds ratio. aOR: Odds ratio adjusted.

Finally, a multivariate analysis was performed where the following statistical associations were found about the risk of PTSD:

Risk factors were identified as having a delivery plan that was not respected (aOR: $2.85,95 \%$ CI 1.56-5.21), have a scheduled caesarean delivery (aOR: $2.53,95 \%$ CI 1.02-2.26), having an emergency caesarean section (aOR: 3.58, 95\% CI 1.83-6.99), admission of the newborn to the neonatal intermediate care unit (aOR: 4.95, 95\% CI 2.36-10.36), admission to the intensive care unit (aOR: $2.25,95 \%$ CI 1.02-4.97), newborn formula-fed on discharge (aOR: 3.57, 95\% CI 1.32-9.62), experiencing verbal obstetric violence (aOR: 5.07, 95\% CI 2.98- 8.63) and psycho-affective obstetric violence (aOR: 2.61, 95\% CI 1.45-4.67).

Protective factors were identified as initiating lactation in the first hour postpartum (aOR: $0.48,95 \%$ CI $0.26-0.87$ ), as well as the perception of support by the couple during pregnancy, childbirth and the puerperium, with an aOR of 0.16 (95\% CI 0.04-0.63) for some support, an aOR of 0.17 (95\% CI 0.05-0.57) for quite a bit of support, and an aOR of 0.17 (95\% CI 0.06-0.53) for a lot of support.

\section{Discussion}

Approximately 13 out of 100 women had a high risk of PTSD. Women with a delivery plan that was not respected, had given birth by scheduled or urgent caesarean section, or had suffered verbal and psycho-affective violence had a higher incidence of PTSD. Mothers of infants admitted to intensive care, or whose infants were formula-fed at discharge also showed a higher incidence of this disorder. Those women who started breastfeeding in the first hour postpartum and felt supported by their partner had a lower risk of developing PTSD.

The study sample is representative of the reference population. The risk of PTSD was detected using a validated instrument [37] that has already been used previously in populations similar to ours [38]. Due to the nature of a questionnaire, there may be a selection bias associated with non-response; however, as the sample is large and representative, we do not think that the responses of those women who did not participate could differ too much from those who did form part of the sample. It is important to note that the number of women who did not respond was low, 53 in total (5.57\%). The questions and possible answers were simple, understandable, and easy to understand for any education level, minimizing any possibility of information bias. The information was collected in a short time range, and although we cannot completely rule out a memory bias, we believe that its impact on the results is minimal. Completely ruling out a confounding bias is impossible, although attempts have been made to control this through study design and adjusting for confounding variables during data analysis. The absence of an official record where obstetric violence appears and the self-declared nature of the violence experienced by women is one of the limitations of the study as it is a subjective experience situation. The questionnaire was provided online, which may limit the participation of women who do not have access to the network. However, this would be a rare occurrence as the use of smartphones, tablets, or computers is common in the current population. The online ques- 
tionnaire tool has been included in previous research as a method of data collection [18,39]. Dichotomizing Perinatal Post-traumatic Stress Disorder Questionnaire Score at 19 indicates that we believe there is little or no difference scoring between 1 and 18, or scoring between 19 and 56. The only difference occurs between those scores 18 and 19. The risk of PTSD was considered a score of $\geq 19$ points. We dichotomized this variable at 19 because past research established this as the score at which risk for PTSD rises [37].

The PTSD incidence in our results is within the range found by Beck and Casavant [3] in their systematic review of 59 studies, where they placed the prevalence of PTSD between $0.8 \%$ and $26 \%$. Our results are also very similar to those found by Vignato et al. [40], in a study developed in the United States, including four systematic reviews, two metaanalyses, and 11 more articles (not included in the previous ones), although the range reported was wide. Other authors found figures somewhat higher than those identified in our results. van Heumen et al. found that $17.4 \%$ of the participants met PTSD criteria, using data collected with a 35-item questionnaire that included a validated PTSD screening in a study conducted in the Netherlands, in which women with at least one traumatic experience during childbirth between 2005 and 2016 participated [22].

The appearance of PTSD was associated with a lack of respect and non-compliance with the birth plan by professionals, in line with what was reported in a cross-sectional study conducted in Spain with 2990 women [36] where they identified that a birth plan that professionals had respected was a protective factor against the development of PTSD. A caesarean delivery, whether scheduled or urgent, was associated with a higher incidence of PTSD, coinciding with that found by other authors [36]. Of the 5332 women who participated in a study conducted in England, $23 \%$ of women who underwent an emergency caesarean section and $16 \%$ of those who had a scheduled caesarean section reported at least 1 or more symptoms of PTSD, thus considering caesarean section a risk factor [41] Also consistent with our results, in a study conducted in Sweden, higher levels of mental distress were found in women who had an emergency or scheduled caesarean section [42]. These results, however, contrast with those found by Mahmoodi et al., in a study involving 240 women in Iran [43], where PTSD was not associated with the type of delivery the woman had experienced. Also in contrast with our findings are those of Olieman et al. [44], in their systematic review including three articles, which identified vaginal delivery as a risk factor, especially when the woman's preference was to give birth by caesarean section, thus suggesting that a caesarean section may become a protective factor against PTSD.

The admission of the newborn to some type of unit, whether intermediate or intensive care, also showed an association with the appearance of PTSD. This contrasts with that reported in a study carried out by Aftyka et al. in Poland with 39 mothers whose babies had been admitted to the intensive care unit [45], in which no association between both variables was found. However, Kim et al. reported results similar to those found in our study [38], identifying an association between the appearance of early or late PTSD and neonates admitted to neonatal intensive care units. Furthermore, the PTSD screening method used in this study coincides with that used in our research, the Perinatal Post-traumatic Stress Disorder Questionnaire (PPQ). Other authors included not only the admission to intensive care units occurred but also the duration of admission. Lefkowitz et al. [46], found an association between a minimum stay of 30 days and the appearance of the disorder. This may be due to the mother-child pairing separation resulting from the admission, and this can cause stress to the mother.

Verbal and psycho-affective obstetric violence also show an association with the appearance of the PTSD, with verbal violence being the most likely to affect the development of this disorder. Appropriate verbal treatment, giving concrete and understandable information, as well as ensuring informed consent have been highlighted by van Dinter-Douma et al. [47], as elements that could help reduce fear during childbirth. The impact of a negative experience during childbirth and PTSD has been considered by the Spanish Ministry of Health in its national delivery care strategy, describing PTSD as an obstetric sequela [48]. 
Early breastfeeding, started in the baby's first hour of life, was identified as a protective factor in the appearance of PTSD. These results coincide with Garthus-Niegel et al. [24], where they found an association between postpartum PTSD and not initiating breastfeeding. In this study, data was collected from the birth records of a Norwegian hospital and questionnaires administered to the 1480 women who participated. They also found an association between not maintaining this type of lactation during the first year and the appearance of PTSD. A systematic review that included 21 studies also found that postpartum PTSD was associated with lower breastfeeding rates, in line with our results [4]. Moreover, based on the results obtained, formula feeding at discharge emerged as a risk factor for PTSD. Imširagić et al. [49], in their study conducted in Croatia involving 259 women, identified lower levels of PTSD in those who continued exclusive breastfeeding for 6-9 weeks postpartum.

The perceived support received from the partner emerged as a protective factor, regardless of the degree of support. No studies exist to date that analyze the relationship between these two variables; highlighting the need for research to increase knowledge in this regard. Although other authors such as Van Heumen et al. [22] have studied support, but from the perspective of social support, identifying it as a protective factor for the appearance of the disorder. The perception of the woman who has support may make her feel protected and supported in the face of possible complications, inconveniences, or doubts that arise, reducing the possibility of stress appearing during childbirth.

\section{Conclusions}

There are clinical practices that are related to the risk of PTSD, including the type of delivery a woman has, formula-fed newborn at hospital discharge, mother-child separation, her birth plan not being respected, and verbal and psycho-affective obstetric violence. Partner support and initiation of breastfeeding in the first hour were identified as protective factors against PTSD. Practices such as breastfeeding or feeling supported during the birthing process can provide resources for women to empower themselves and cope with a possible risk of postpartum post-traumatic stress disorder, and prevent its onset. Professionals need to be sensitized to this topic since the treatment and care they provide to women can influence the probability of developing PTSD.

Author Contributions: Conceptualization-S.M.-V. and J.M.M.-G.; Methodology-S.M.-V., A.H.-M., and J.M.M.-G.; Formal Analysis-A.H.-M. and J.R.-A.; Writing-Original Draft Preparation-S.M.-V. and J.M.M.-G.; Writing-Review \& Editing-S.M.-V., A.H.-M., J.R.-A. and J.M.M.-G.; SupervisionJ.M.M.-G. and A.H.-M.; Project Administration-A.H.-M. All authors have read and agreed to the published version of the manuscript.

Funding: This research received no external funding.

Institutional Review Board Statement: This study was approved by the Clinical Research Ethics Committee of Universidad de Jaen (reference number TD-VCDEPP-2019/1417-N-19). Before starting the questionnaire, the participants read a fact sheet about the study, its objectives, etc., and marked a box by which they showed their consent to participate in it, i.e., they signed an online informed consent (ticking the option if they wanted to participate or not doing so when refusing to take part in the study). We followed the protocols established to carry out this type of research with the purpose of publication/disclosure to the scientific community. The study was conducted according to the strobe guidelines set in the Declaration of Helsinki and all procedures involving human subjects were approved by the Ethics Committee. All women involved in this study filled out informed consent and data treatment forms to enter the study, in accordance with the ethical standards of the Ethics Committee. All participants received written information on the study, including the fact that participation was entirely voluntary with anonymity guaranteed.

Informed Consent Statement: Informed consent was obtained from all subjects involved in the study.

Data Availability Statement: The datasets generated and/or analyzed during the current study are available from the corresponding author on reasonable request. 
Conflicts of Interest: The authors declare no competing interests. No conflict of interest has been declared by the authors. This research received no specific grant from any funding agency in the public, commercial, or not-for-profit sectors.

\section{References}

1. WHO. Mental Health Aspects of Women's Reproductive Health: A Global Review of the Literature. WHO Press, 2009. Available online: http:/ / apps.who.int/iris/bitstream/handle/10665/43846/9789241563567_eng.pdf;jsessionid=1A812923347FE5054B9 FAFCA9CCA9E96? sequence $=1$ (accessed on 15 October 2020).

2. Flores-Ramos, M. Mental health in pregnant women. Perinatol Hum Reprod. 2013, 27, 4-143.

3. Beck, C.T.; Casavant, S. Synthesis of Mixed Research on Posttraumatic Stress Related to Traumatic Birth. J. Obstet. Gynecol. Neonatal Nurs. 2019, 48, 385-397. [CrossRef]

4. Cook, N.; Ayers, S.; Horsch, A. Maternal posttraumatic stress disorder during the perinatal period and child outcomes: A systematic review. J. Affect. Disord. 2018, 225, 18-31. [CrossRef]

5. Grekin, R.; O'Hara, M.W. Prevalence and risk factors of postpartum posttraumatic stress disorder: A meta-analysis. Clin. Psychol. Rev. 2014, 34, 389-401. [CrossRef] [PubMed]

6. Khoramroudi, R. The prevalence of posttraumatic stress disorder during pregnancy and postpartum period. J. Fam. Med. Prim. Care 2018, 7, 220-223. [CrossRef]

7. Dikmen-Yildiz, P.; Ayers, S.; Phillips, L. Factors associated with post-traumatic stress symptoms (PTSS) 4-6 weeks and 6 months after birth: A longitudinal population-based study. J. Affect. Disord. 2017, 221, 238-245. [CrossRef] [PubMed]

8. Yildiz, P.D.; Ayers, S.; Phillips, L. The prevalence of posttraumatic stress disorder in pregnancy and after birth: A systematic review and meta-analysis. J. Affect. Disord. 2017, 208, 634-645. [CrossRef]

9. Ayers, S. Delivery as a Traumatic Event: Prevalence, Risk Factors, and Treatment for Postnatal Posttraumatic Stress Disorder. Clin Obstet. Gynecol. 2004, 47, 552-567. [CrossRef]

10. Olde, E.; van der Hart, O.; Kleber, R.; van Son, M. Posttraumatic stress following childbirth: A review. Clin. Psychol. Rev. 2006, 26, 1-16. [CrossRef]

11. Ferguson, R. Recognizing postpartum posttraumatic stress disorder. Nursery 2018, 48, 14. [CrossRef]

12. Garthus-Niegel, S.; Horsch, A.; Handtke, E.; Von Soest, T.; Ayers, S.; Weidner, K.; Eberhard-Gran, M. The Impact of Postpartum Posttraumatic Stress and Depression Symptoms on Couples' Relationship Satisfaction: A Population-Based Prospective Study. Front. Psychol. 2018, 9, 1728. [CrossRef] [PubMed]

13. Nerum, H.; Halvorsen, L.; Sørlie, T.; Øian, P. Maternal Request for Cesarean Section due to Fear of Birth: Can It Be Changed Through Crisis-Oriented Counseling. Birth 2006, 33, 221-228. [CrossRef]

14. Wilson, C.K.; Padron, E.; Samuelson, K.W. Trauma Type and Posttraumatic Stress Disorder as Predictors of Parenting Stress in Trau-ma-Exposed Mothers. Violence Vict. 2017, 32, 141-158. [CrossRef] [PubMed]

15. Beck, C.T. Post-traumatic stress disorder due to childbirth: The aftermath. Nurs Res. 2004, 53, 216-224. [CrossRef]

16. Lev-Wiesel, R.; Daphna-Tekoah, S.; Hallak, M. Childhood sexual abuse as a predictor of birth-related posttraumatic stress and post-partum posttraumatic stress. Child Abus Negl. 2009, 33, 877-887. [CrossRef] [PubMed]

17. Muzik, M.; McGinnis, E.W.; Bocknek, E.; Morelen, D.; Rosenblum, K.L.; Liberzon, I.; Seng, J.; Abelson, J.L. PTSD Symptoms Across Pregnancy and Early Postpartum Among Women with Lifetime PTSD Diagnosis. Depress. Anxiety 2016, 33, 584-591. [CrossRef] [PubMed]

18. Hernández-Martínez, A.; Rodríguez-Almagro, J.; Molina-Alarcón, M.; Infante-Torres, N.; Rubio-Álvarez, A.; Martínez-Galiano, J.M. Peri-natal factors related to post-traumatic stress disorder symptoms 1-5 years following birth. Women Birth. 2020, 33, 129-135. [CrossRef]

19. Zaat, T.R.; van Steijn, M.E.; de Haan-Jebbink, J.M.; Olff, M.; Stramrood, C.A.I.; van Pampus, M.G. Posttraumatic stress disorder related to postpartum haemorrhage: A systematic review. Eur. J. Obstet. Gynecol. Reprod. Biol. 2018, 225, 20-214. [CrossRef]

20. Çapik, A.; Durmaz, H. Fear of Childbirth, Postpartum Depression, and Birth-Related Variables as Predictors of Posttraumatic Stress Disorder After Childbirth. Worldviews Evid. Based Nurs. 2018, 15, 455-463. [CrossRef]

21. Angelini, C.R.; Pacagnella, R.C.; Parpinelli, M.A.; Silveira, C.; Andreucci, C.B.; Ferreira, E.C. Post-Traumatic Stress Disorder and se-vere maternal morbidity: Is there an association? Clinics 2018, 73, 309. [CrossRef]

22. van Heumen, M.A.; Hollander, M.H.; van Pampus, M.G.; van Dillen, J.; Stramrood, C.A. Psychosocial Predictors of Postpartum Posttrau-matic Stress Disorder in Women with a Traumatic Childbirth Experience. Front. Psychiatry 2018, 9, 348. [CrossRef] [PubMed]

23. Dekel, S.; Stuebe, C.; Dishy, G. Childbirth Induced Posttraumatic Stress Syndrome: A Systematic Review of Prevalence and Risk Factors. Front. Psychol. 2017, 8, 560. [CrossRef] [PubMed]

24. Garthus-Niegel, S.; Horsch, A.; Ayers, S.; Junge-Hoffmeister, J.; Weidner, K.; Eberhard-Gran, M. The influence of postpartum PTSD on breastfeeding: A longitudinal population-based study. Birth 2018, 45, 193-201. [CrossRef]

25. Thomson, G.; Downe, S. Widening the trauma discourse: The link between childbirth and experiences of abuse. J. Psychosom. Obstet. Gynecol. 2008, 29, 268-273. [CrossRef] 
26. Sando, D.; Abuya, T.; Asefa, A.; Banks, K.P.; Freedman, L.P.; Kujawski, S.; Markovitz, A.; Ndwiga, C.; Ramsey, K.; Ratcliffe, H.; et al. Methods used in prevalence studies of disrespect and abuse during facility based childbirth: Lessons learned. Reprod. Health 2017, 14, 1-18. [CrossRef] [PubMed]

27. Bohren, M.A.; Mehrtash, H.; Fawole, B.; Maung, T.M.; Balde, M.D.; Maya, E. How women are treated during facility-based childbirth in four countries: A cross-sectional study with labour observations and community-based surveys. Lancet 2019, 394, 1750-1763. [CrossRef]

28. Siraj, A.; Teka, W.; Hebo, H. Prevalence of disrespect and abuse during facility based child birth and associated factors, Jimma University Medical Center, Southwest Ethiopia. BMC Pregnancy Childbirth 2019, 19, 1-9. [CrossRef]

29. Martínez-Galiano, J.M.; Martinez-Vazquez, S.; Rodríguez-Almagro, J.; Hernández-Martinez, A. The magnitude of the problem of obstetric violence and its associated factors: A cross-sectional study. Women Birth 2020, S1871-5192(20)30359-0. [CrossRef]

30. World Health Organization. WHO recommendations on health promotion interventions for maternal and newborn health. Matern. Newborn Child Adolesc. Health 2015, 1, 90.

31. Ayers, S.; Bond, R.; Bertullies, S.; Wijma, K. The aetiology of post-traumatic stress following childbirth: A meta-analysis and theoretical framework. Psychol. Med. 2016, 46, 1121-1134. [CrossRef]

32. Andersen, L.B.; Melvaer, L.B.; Videbech, P.; Lamont, R.F.; Joergensen, J.S. Risk factors for developing post-traumatic stress disorder following childbirth: A systematic review. ACTA Obstet. Gynecol. Scand. 2012, 91, 1261-1272. [CrossRef]

33. Callister, L.C. Making meaning: Women's birth narratives. J. Obstet. Gynecol. Neonatal. Nurs. JOGNN 2004, 33, 508-518. [CrossRef] [PubMed]

34. Dekel, S.; Thiel, F.; Dishy, G.; Ashenfarb, A.L. Is childbirth-induced PTSD associated with low maternal attachment? Arch. Women. Ment. Health 2019, 22, 119-122. [CrossRef]

35. Peduzzi, P.; Concato, J.; Kemper, E.; Holford, T.R.; Feinstein, A.R. A simulation study of the number of events per variable in logistic regression analysis. J. Clin. Epidemiol. 1996, 49, 1373-1379. [CrossRef]

36. Martínez, A.H.; Rodríguez-Almagro, J.; Molina-Alarcón, M.; Infante-Torres, N.; Manzanares, M.D.; Martínez-Galiano, J.M. Postpartum post-traumatic stress disorder: Associated perinatal factors and quality of life. J. Affect. Disord. 2019, 249, 143-150. [CrossRef] [PubMed]

37. Callahan, J.L.; Borja, S.E.; Hynan, M.T. Modification of the Perinatal PTSD Questionnaire to enhance clinical utility. J. Perinatol. 2006, 26, 533-539. [CrossRef]

38. Kim, W.J.; Lee, E.; Kim, K.R.; Namkoong, K.; Park, E.S.; Rha, D.-W. Progress of PTSD symptoms following birth: A prospective study in mothers of high-risk infants. J. Perinatol. 2015, 35, 575-579. [CrossRef]

39. Smith, T.; Gemmill, A.W.; Milgrom, J. Perinatal anxiety and depression: Awareness and attitudes in Australia. Int. J. Soc. Psychiatry 2019, 65, 378-387. [CrossRef] [PubMed]

40. Vignato, J.; Georges, J.M.; Bush, R.A.; Connelly, C.D. Post-traumatic stress disorder in the perinatal period: A concept analysis. J. Clin. Nurs. 2017, 26, 3859-3868. [CrossRef] [PubMed]

41. Rowlands, I.J.; Redshaw, M. Mode of birth and women's psychological and physical wellbeing in the postnatal period. BMC Pregnancy Childbirth 2012, 12, 138. [CrossRef]

42. Ryding, E.L.; Wijma, K.; Wijma, B. Psychological impact of emergency cesarean section in comparison with elective cesarean section, instrumental and normal vaginal delivery. J. Psychosom. Obstet. Gynaecol. 1998, 19, 135-144. [CrossRef] [PubMed]

43. Mahmoodi, Z.; Dolatian, M.; Shaban, Z.; Shams, J.; Alavi-Majd, H.; Mirabzadeh, A. Correlation between Kind of Delivery and Posttrau-matic Stress Disorder. Ann. Med. Health Sci. Res. 2016, 6, 61-356.

44. Olieman, R.M.; Siemonsma, F.; Bartens, M.A.; Garthus-Niegel, S.; Scheele, F.; Honig, A. The effect of an elective cesarean section on maternal request on peripartum anxiety and depression in women with childbirth fear: A systematic review. BMC Pregnancy Childbirth 2017, 17, 1-8. [CrossRef]

45. Aftyka, A.; Rybojad, B.; Rozalska-Walaszek, I.; Rzoñca, P.; Humeniuk, E. Post-traumatic stress disorder in parents of children hospitalized in the neonatal intensive care unit (NICU): Medical and demographic risk factors. Psychiatr. Danub. 2014, 26, 347-352.

46. Lefkowitz, D.S.; Baxt, C.; Evans, J.R. Prevalence and correlates of posttraumatic stress and postpartum depression in parents of in-fants in the Neonatal Intensive Care Unit (NICU). J. Clin. Psychol. Med. Settings 2010, 17, 7-230. [CrossRef] [PubMed]

47. van Dinter-Douma, E.E.; de Vries, N.E.; Aarts-Greven, M.; Stramrood, C.A.I.; van Pampus, M.G. Screening for trauma and anxiety recognition: Knowledge, management and attitudes amongst gynecologists regarding women with fear of childbirth and postpartum post-traumatic stress disorder. J. Matern. Fetal. Neonatal. Med. 2018, 12, 1-281. [CrossRef]

48. Spanish Ministry of Health. Strategy on Care for Normal Childbirth in the National Health System (Spain). Clin. Pract. Guidel. Care Norm. Childbirth. 2015. Available online: https://www.mscbs.gob.es/organizacion/sns/planCalidadSNS/pdf/ InformeFinalEAPN_revision8marzo2015.pdf (accessed on 15 October 2020).

49. Imširagić, A.S.; Begić, D.; Sarajlić, I.; Palavra, I.R.; Orban, M. Predictors of Exclusive Breastfeeding 6-9 Weeks After Delivery: A Pro-spective Cohort Study. Public Mental Health Perspective. Psychiatr. Danub. 2016, 28, 395-403. 